\title{
Fracture Toughness Evaluation of Thin Fe-Al Intermetallic Compound Layer at Reactive Interface between Dissimilar Metals ${ }^{* 1}$
}

\author{
Nobuhiko Kyokuta*2, Masaki Koba*2, Toshio Araki*3, Shoichi Nambu, \\ Junya Inoue and Toshihiko Koseki \\ Department of Materials Engineering, Graduate School of Engineering, The University of Tokyo, Tokyo 113-8656, Japan
}

The fracture toughness of $\mathrm{Fe}-\mathrm{Al}$ intermetallic compounds (IMCs), $\mathrm{FeAl}$ and $\mathrm{Fe}_{2} \mathrm{Al}_{5}$, that form as a thin layer on steel substrate was investigated. A model for evaluating the fracture toughness of a brittle thin layer on an elastoplastic substrate was applied, and the fracture toughness was evaluated from the thickness of the IMC layer and the crack interval in the IMC layer after uniaxial tensile testing. The phase and microstructure of the IMC layer were varied to investigate their effects on the fracture toughness of the IMC. The relationship between layer thickness and crack interval was in a good agreement with the theoretical model, and the fracture toughness was evaluated adequately using the model. It was clarified that $\mathrm{FeAl}$ has higher fracture toughness than $\mathrm{Fe}_{2} \mathrm{Al}_{5}$, and that fine-grained $\mathrm{Fe}_{2} \mathrm{Al}_{5}$ has higher fracture toughness than coarse-grained $\mathrm{Fe}_{2} \mathrm{Al}_{5}$. [doi:10.2320/matertrans.M2012425]

(Received January 7, 2013; Accepted March 19, 2013; Published April 26, 2013)

Keywords: fracture toughness, intermetallic compound

\section{Introduction}

Recently, a number of methods for bonding dissimilar metals, including steel/Al bonding ${ }^{1,2)}$ and steel/Mg bonding, ${ }^{3)}$ have been studied in order to produce lightweight metallic composite materials. It has been found that a brittle $\mathrm{Fe}-\mathrm{Al}$ intermetallic compound (IMC) layer is formed at the interface between such dissimilar metals. The formation of the same kind of $\mathrm{Fe}-\mathrm{Al}$ IMC layer has also been reported in aluminizing and galvanizing processes. It is widely recognized that such a formation of the Fe-Al IMC layer at these interfaces influences the reliability of the composite materials by degrading the bonding strength of the interface between dissimilar materials and the adhesion of the coating layer. Therefore, it is very important to clarify the mechanical properties of these IMC layers. Oikawa et al. studied the relationship between the thickness of the Fe-Al IMC layer and the peel strength in steel/Al joints and reported that the peel strength decreases considerably when the thickness of the IMC layer exceeds $2 \mu \mathrm{m} .^{1)}$ Furthermore, Mukae et al. reported that the shear strength of the interface between steel and aluminum decreases markedly when the thickness of the $\mathrm{Fe}-\mathrm{Al}$ IMC layer in aluminum-clad steel exceeds $1.5 \mu \mathrm{m}^{2}{ }^{2}$ Thus, it is generally believed that for practical purposes, the thickness of the $\mathrm{Fe}-\mathrm{Al}$ IMC layer at the interface between dissimilar metals should be less than $1 \mu \mathrm{m}$. Even though it is clear that the thickness of the Fe-Al IMC layer influences the interface strength, the dominant factors that explain the relationship between the thickness of the Fe-Al IMC layer and the interface strength between dissimilar metals have not been clarified, partly because of the fact that the fracture toughness of the $\mathrm{Fe}-\mathrm{Al} \mathrm{IMC}$ layer formed at the interface is still unknown.

\footnotetext{
${ }^{* 1}$ This Paper was Originally Published in Japanese in J. Japan Inst. Metals 76 (2012) 272-277.

${ }^{* 2}$ Graduate Student, The University of Tokyo

${ }^{* 3}$ Graduate Student, The University of Tokyo. Present address: FurukawaSky Aluminum Corp., Fukaya 366-8511, Japan
}

To measure the fracture toughness of a brittle material such as an IMC, the indentation fracture method has been widely applied. In this method, the fracture toughness is evaluated from the crack length induced by forcing an indenter tip into the surface of a brittle material. ${ }^{4)}$ Recently, the microscale evaluation of fracture toughness has been attempted using a nanoindenter. ${ }^{5)}$ However, the crack size is still in the order of microns to allow for an accurate measurement even with a nanoindenter, which means that it is difficult to evaluate the fracture toughness of brittle thin materials with thickness in the order of submicrons.

In this study, we propose a method for evaluating the fracture toughness of thin $\mathrm{Fe}-\mathrm{Al}$ IMC layers formed at the interface between dissimilar metals, applying fracture mechanics. The method enables us to evaluate the fracture toughness of brittle materials on a submicron scale, and consequently, to analyze the relationship between the fracture toughness and both the composition and the microstructure of Fe-Al IMC layers.

\section{Theory}

In a brittle thin layer formed on a substrate, a tensile stress is induced as a result of either substrate deformation or residual stress, such as lattice-misfit distortion and thermal stress. As a result of the tensile stress, various configurations of cracks form. ${ }^{6-13)}$ It is known that when the substrate is subject to a uniaxial tensile deformation, steady-state cracks begin to propagate in the brittle layer in the direction perpendicular to the maximum principal stress as the applied stress reaches the critical stress $\sigma_{\mathrm{c}}$. The density of these steady-state cracks increases further with increasing tensile strain, and ultimately the crack interval asymptotically approaches a constant value $\lambda_{\mathrm{c}} \cdot{ }^{7-13)}$ In a metal substrate, plastic deformation occurs just below the crack, and the plastic zone is expected to be small if the substrate is sufficiently hard. In this case, it has been reported that the critical stress $\sigma_{\mathrm{c}}$ and the final crack interval $\lambda_{\mathrm{c}}$ can be given as 

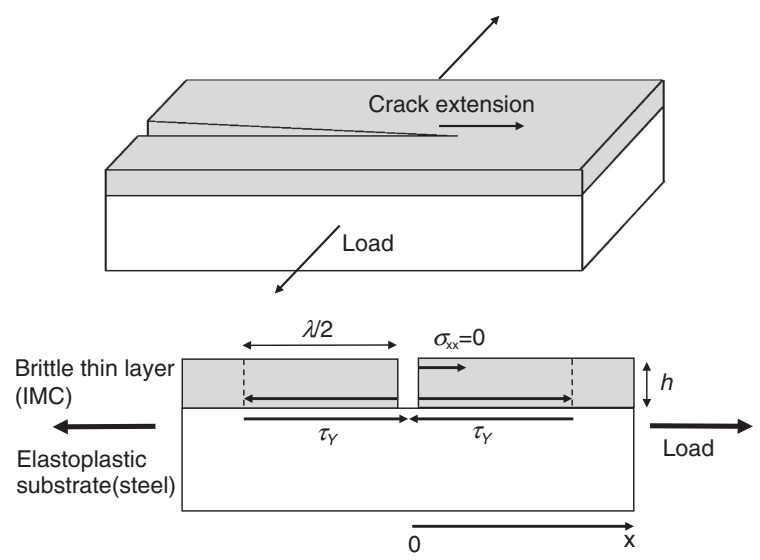

Fig. 1 Schematic illustration of the shear-lag model.

a function of the film thickness $h$ on the basis of the linear elastic fracture mechanics model. ${ }^{8,12)}$ On the other hand, if the substrate is soft, the plastic zone induced in the substrate expands and eventually covers the entire substrate surface. In this case, it has been quantitatively shown that the critical stress $\sigma_{\mathrm{c}}$ and the final crack interval $\lambda_{\mathrm{c}}$ can be given as functions of the brittle layer thickness $h$ using the shear lag limit model, in which it is assumed that the substrate is perfect elastoplastic body. ${ }^{7,13)}$ In this study, the latter model is more appropriate, because our metallic substrates are very ductile.

In the shear lag limit model, it is assumed that the substrate material is a perfect elastoplastic body. In this case, as shown in Fig. 1, plastic deformation occurs in the substrate while steady-state cracks extend in the direction perpendicular to that of the maximum principle stress in the brittle layer. The plastic zone is concentrated near the interface with the brittle layer, and large slip deformation accumulates only in the plastic zone. Then, the plastic deformation releases part of the stress $\sigma$ acting on the brittle layer, and the stress component perpendicular to the crack surface becomes zero on the crack surface. In addition, the shear stress $\tau_{\mathrm{Y}}$ at the interface between dissimilar metals takes a constant value, $\tau_{\mathrm{Y}}=\sigma_{\mathrm{Y}} / \sqrt{3}$, over the whole interface between the dissimilar metals, where $\sigma_{\mathrm{Y}}$ is the yield strength of the substrate. Therefore, the energy release rate $\Delta G$ upon crack extension can be given by subtracting the energy dissipated by interface sliding $\Delta W_{\mathrm{d}}$ from the sum of the work done by the applied load $\Delta W$ and the change in strain energy released by interface sliding $\Delta U_{\mathrm{s}}{ }^{7,13)}$

$$
\Delta G=\Delta W+\Delta U_{\mathrm{s}}-\Delta W_{\mathrm{d}}=\frac{\sigma^{3} h^{2}}{3 E \tau_{\mathrm{Y}}}=h \Gamma
$$

Here, $E$ is Young's modulus of the brittle layer and $\Gamma$ is the fracture toughness of the brittle layer. On the other hand, the force balance at the interface is given by

$$
\sigma h=\lambda \tau_{\mathrm{Y}} / 2
$$

where $\lambda / 2$ is the length of the plastic deformation region in the substrate. Therefore, the stress $\sigma_{\mathrm{cr}}$ that can induce steadystate cracks under the general yielding conditions is given by

$$
\sigma_{\mathrm{cr}}=\sqrt[3]{\frac{3 E \Gamma \tau_{\mathrm{Y}}}{h}}
$$

Finally, the saturated crack interval $\lambda_{\mathrm{c}}$ is given by the minimum length of the plastic deformation region that can induce the tensile stress $\sigma_{\mathrm{c}}$ in the brittle layer.

$$
\lambda_{\mathrm{c}}=2\left(\frac{9 E \Gamma h^{2}}{\sigma_{\mathrm{Y}}^{2}}\right)^{1 / 3}
$$

It is noted that in the above discussion, we have assumed that the substrate is a perfect elastoplastic solid. However, the actual crack interval $\lambda_{\mathrm{c}}$ is expected to deviate from eq. (4) because of the influence of work hardening of the substrate and the difference between the elastic constants of the substrate and those of the thin layer. The influences of work hardening and the different elastic constants on the energy release rate $\Delta G$ were numerically verified by Beuth and Klingbeil. ${ }^{13)}$ It was shown that when the elastic constant of the substrate and that of the thin layer satisfy $\alpha=$ $\frac{E_{1}-E_{2}}{E_{1}+E_{2}}<0.5$, it is possible to estimate $\Delta G$ using the shear lag limit model with the average yield stress $\sigma_{\text {Yeff }}$ at the interface (effective yield stress) as a substitute for the yield strength $\sigma_{\mathrm{Y}}$ of the substrate. In addition, the results of the numerical computation show that the effective yield stress $\sigma_{\text {Yeff }}$ does not depend on the length of the plastic deformation region and is almost constant as a function of the work hardening exponent.

In this study many steady-state cracks are generated in the IMC layer by loading various magnitudes of uniaxial tensile load on the steel substrate. Fe-Al IMC layers with various compositions and microstructures are formed, and the corresponding crack intervals $\lambda_{\mathrm{c}}$ are measured. At the same time, the yield stress $\sigma_{\text {Yeff }}$ near the interface is measured with a nanoindenter, and finally, the fracture toughness is examined with respect to the composition and microstructure using eq. (4).

\section{Experimental}

To form uniform IMC layers with different compositions and microstructures, three different methods, namely, the reactive transient liquid phase (TLP) bonding method, the hot-dipping method, and the infiltration method, were used. The chemical compositions of the steel substrates and $\mathrm{Mg}$ alloys used in this study are shown in Tables 1 and 2, respectively.

In the reactive TLP bonding method, pure Ag with a thickness of $1 \mu \mathrm{m}$ was first deposited onto the surfaces of interstitial-free (IF) steel and SUS304 by the electron-beam deposition method. The steel and $\mathrm{Mg}$ alloy were stacked so that the steel/ $\mathrm{Ag} / \mathrm{Mg} / \mathrm{Ag} /$ steel layer structure was achieved, and then the stacked specimen was heated at $773 \mathrm{~K}$ for 3000 to $30000 \mathrm{~s}$ with a compression stress of $1 \mathrm{MPa}$ in argon gas atmosphere, followed by furnace-cooled.

In the hot-dipping method, the $84 \mathrm{~mol} \% \mathrm{Mg}-16 \mathrm{~mol} \% \mathrm{Ag}$ eutectic alloy melt was prepared with an additional 3 to $4 \%$ Al. In a crucible, the IF steel was immersed in the $\mathrm{Mg}-\mathrm{Ag}$ eutectic alloy melt at $773 \mathrm{~K}$ for $2000-5000 \mathrm{~s}$ in argon gas atmosphere and then water-cooled.

In the infiltration method, different $\mathrm{Mg}-\mathrm{Al}$ alloys with $\mathrm{Al}$ concentrations of $1,2,3$ and $4 \mathrm{~mol} \%$ were prepared by mixing pure $\mathrm{Mg}$ and $\mathrm{Mg}$ alloy AZ63. Stacked IF steel sheets with a space and $\mathrm{Mg}-\mathrm{Al}$ alloy were heated at $973 \mathrm{~K}$ in a 
Table 1 Chemical compositions of steel substrates (mass)\%.

\begin{tabular}{cccccccc}
\hline Materials & $\mathrm{C}$ & $\mathrm{Si}$ & $\mathrm{Mn}$ & $\mathrm{P}$ & $\mathrm{S}$ & $\mathrm{Ni}$ & $\mathrm{Cr}$ \\
\hline SUS304 & 0.04 & 0.66 & 1.05 & 0.032 & 0.002 & 8.57 & 18.16 \\
\hline & $\mathrm{C}$ & $\mathrm{Mn}$ & $\mathrm{Cu}$ & & & & \\
\hline IF Steel & 0.001 & 0.16 & 0.22 & & & & \\
\hline
\end{tabular}

Table 2 Chemical compositions of magnesium alloys (mass)\%.

\begin{tabular}{cccccccc}
\hline Materials & $\mathrm{Al}$ & $\mathrm{Zn}$ & $\mathrm{Mn}$ & $\mathrm{Fe}$ & $\mathrm{Si}$ & $\mathrm{Cu}$ & $\mathrm{Ni}$ \\
\hline $\mathrm{AZ31}$ & $2.5-3.5$ & $0.6-1.4$ & $0.2-1.0$ & $<0.005$ & $<0.1$ & $<0.05$ & \\
\hline $\mathrm{AZ61}$ & $5.8-7.2$ & $0.04-1.5$ & $0.15-0.5$ & $<0.005$ & $<0.1$ & $<0.05$ & \\
\hline AZ63 & $5.3-6.7$ & $2.5-3.5$ & $0.15-0.35$ & & 0.3 & 0.25 & 0.01 \\
\hline
\end{tabular}

crucible. The molten $\mathrm{Mg}-\mathrm{Al}$ alloy infiltrated between the stacked IF steel sheets upon applying argon gas pressure. Heating lasted for $900 \mathrm{~s}$, and was followed by then aircooling.

Note that the layered structures of the samples have a triple-layered structure of steel/Mg alloy/steel in the reactive TLP bonding and infiltration methods and a double-layered structure of steel $/ \mathrm{Mg}-\mathrm{Ag}-\mathrm{Al}$ eutectic alloy in the hot-dipping method. A sample of $30 \mathrm{~mm}$ length $\times 6 \mathrm{~mm}$ width was cut from each sample for uniaxial tensile tests. The interfacial IMC layers of the samples after a tensile test were observed from the direction perpendicular to the tensile direction using a field emission scanning electron microscope (FE-SEM). The crack interval $\lambda$ was obtained as the average of more than 50 cracks. At the same time, we identified the IMC phase using X-ray diffraction (XRD), performed composition analysis by energy-dispersive X-ray spectroscopy (EDS), and analyzed the IMC microstructure using electron backscatter diffraction (EBSD). A nanoindenter was used to measure the hardness of the steel substrate near the IMC.

\section{Results}

\subsection{Formation of Fe-Al IMCs}

Cross-sectional SEM images of the Fe-Al IMC obtained by each method are shown in Fig. 2. It was confirmed that a thin and uniform IMC film layer was formed by all the fabrication methods. Figure 3 shows X-ray diffraction spectra obtained from the IMC layers. It was confirmed that $\mathrm{Fe}_{2} \mathrm{Al}_{5}$ mainly formed in the reactive TLP bonding method and the hot-dipping method, whereas $\mathrm{Fe}_{2} \mathrm{Al}_{5}$ and $\mathrm{FeAl}$ formed in the infiltration method. Figure 4 shows an enlarged image of Fig. 2(c). The EDS results show that the formation of FeAl dominates the IMC layer by the infiltration method and that $\mathrm{Fe}_{2} \mathrm{Al}_{5}$ only partly covers the surface of the IMC layer. Therefore, we regard the samples made by the infiltration method as having the single phase of FeAl and disregard $\mathrm{Fe}_{2} \mathrm{Al}_{5}$.

\subsection{Crack interval}

Figure 5(a) shows a cross-sectional image of the interface of the sample at a tensile strain of 10\%, and Fig. 5(b) shows a plan-view image of the IMC layer after the $\mathrm{Mg}$ alloy was
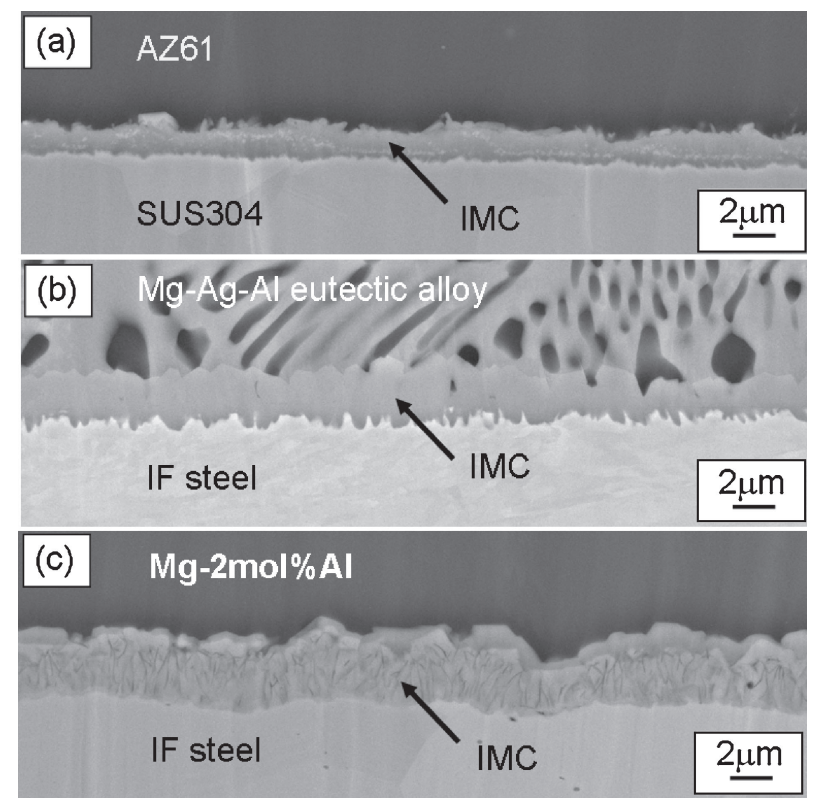

Fig. 2 Cross-sectional images of IMC made by (a) reactive-TLP bonding, (b) hot-dipping method and (c) infiltration method.

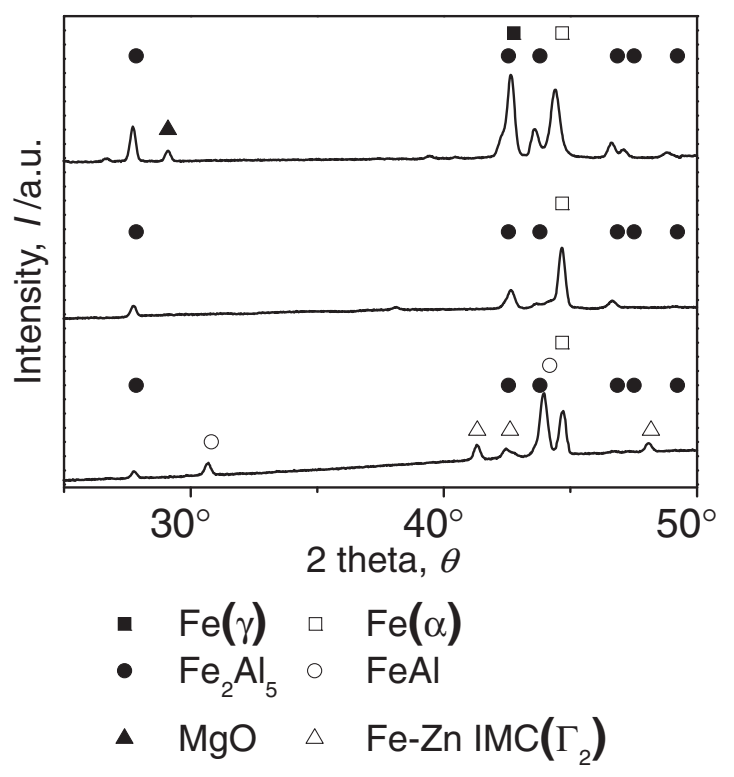

Fig. 3 XRD patterns from the steel surfaces after (a) reactive-TLP bonding, (b) hot-dipping and (c) infiltration.

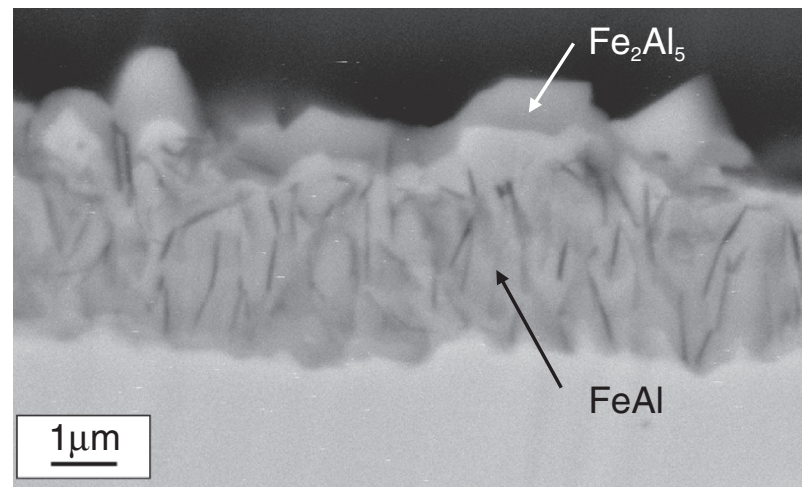

Fig. 4 Close-up image of IMCs shown in Fig. 2(c). 

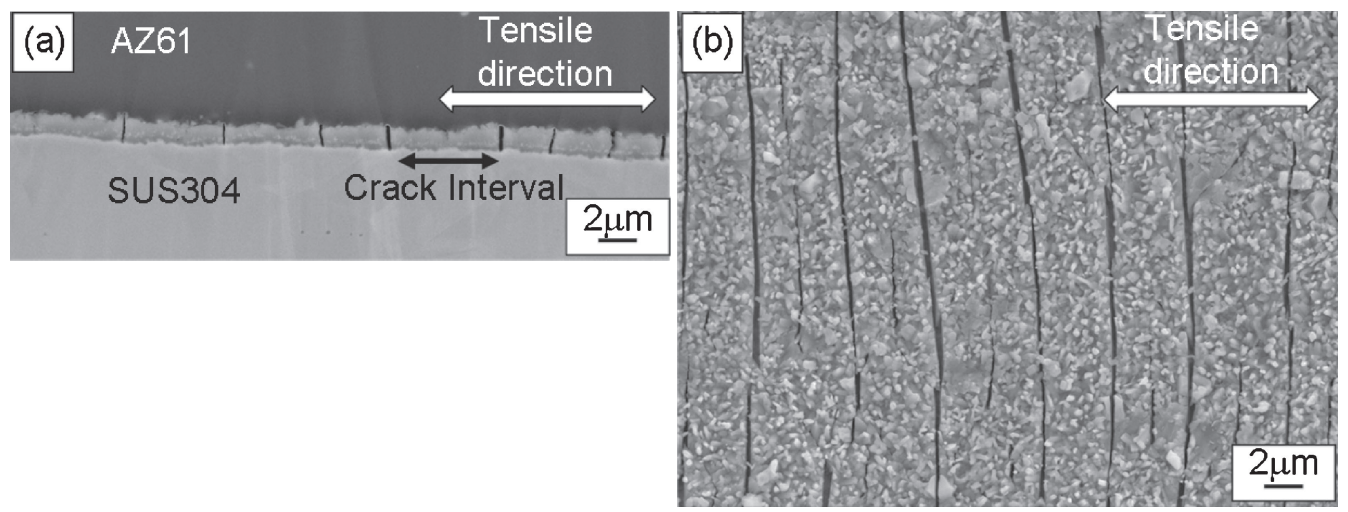

Fig. 5 Cracks observed after uniaxial tensile testing with $10 \%$ strain (a) cross-sectional view and (b) plan view.
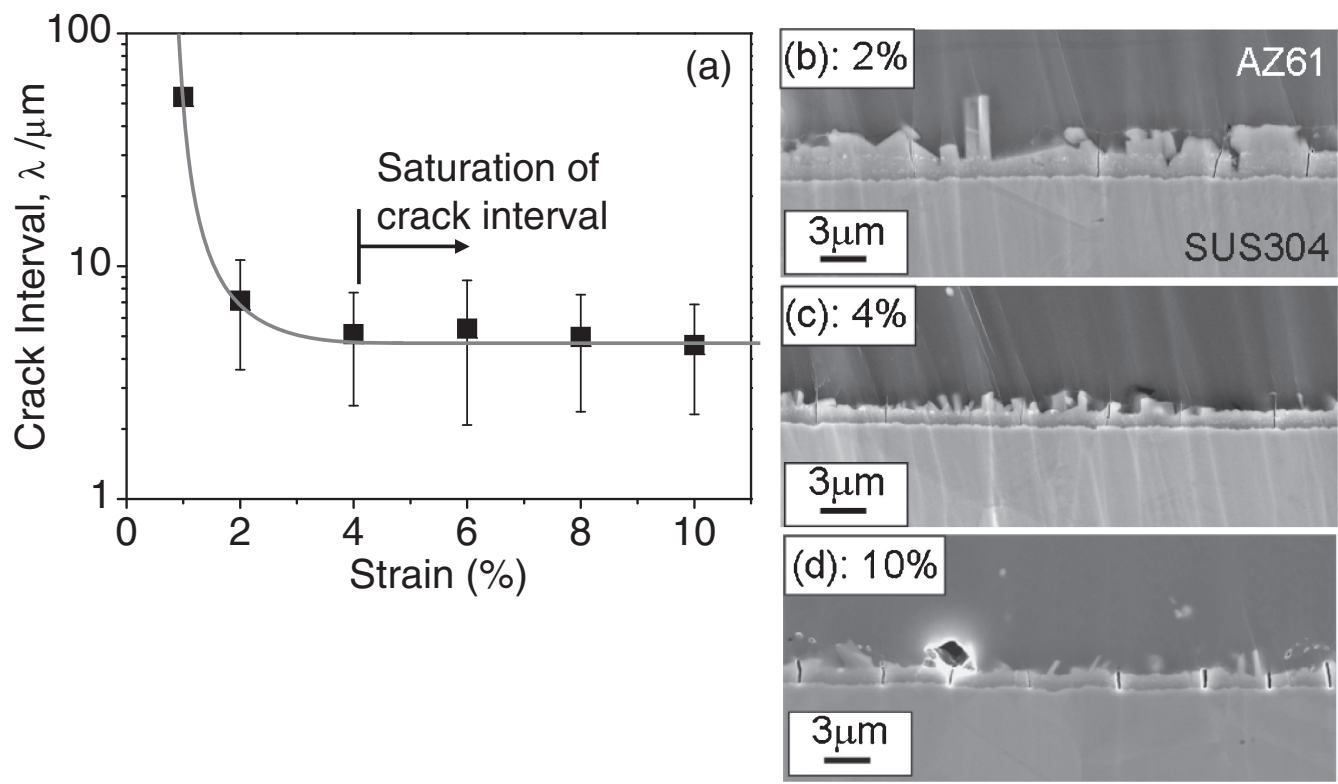

Fig. 6 (a) Relationship between nominal strain and crack interval. Cross-sectional images of cracks in IMC after applying (b) $2 \%$, (c) $4 \%$ and (d) $10 \%$ tensile strain.

dissolved in $\mathrm{HNO}_{3}$ for the same sample. Figure 5 confirms that cracks extend linearly in the direction perpendicular to the tensile direction with regular intervals.

The dependence of the crack interval on tensile strain was also evaluated. Figure 6 shows the relationship between crack interval and tensile strain for the samples (IMC thickness $1.4 \pm 0.25 \mu \mathrm{m}$ ) prepared by the reactive TLP bonding method. It is observed that crack interval remains almost constant among the samples subjected to strains of more than $4 \%$. This suggests that when the applied strain is more than $4 \%$, yielding of the steel substrate occurs entirely near the interface, and then no more cracks form. Therefore, to study the relationship between the thickness of the IMC layer and the crack interval, a tensile strain of $10 \%$ is applied to all samples in this study so that the crack interval is fully saturated.

It should be noted that the Mg alloy layer was not removed from the tensile specimens fabricated by the reactive TLP method and infiltration method, as shown in Fig. 5, even though only the steel substrate and IMC layer are assumed in the shear lag limit model, as shown in Fig. 1. The reason for this is that since the fracture toughness $\Gamma$ is proportional to the square of the yield strength of the substrate, as eq. (4) shows, the effect of the Mg alloy, which has lower yield strength, on the crack interval is small. As discussed in the following section, work hardening is not observed in the $\mathrm{Mg}$ alloy in the vicinity of the IMC layer, although it is pronounced in the steel near the interface. Therefore, it is considered that the $\mathrm{Mg}$ alloy does not contribute to the stress accumulation in the IMC layer. Thus, we ignore the influence of the $\mathrm{Mg}$ alloy. In fact, crack interval was quite similar between specimens with $\mathrm{Mg}$ alloy and those from which $\mathrm{Mg}$ alloy was removed by $\mathrm{HNO}_{3}$.

\subsection{Deformation of steel substrates}

To investigate the work hardening behavior of steel substrates near the interface, the plastic deformation region was analyzed using EBSD and hardness measurement with a nanoindenter for SUS304 and IF steel at a tensile strain of 10\%. The results are shown in Fig. 7(a) for SUS304 and Fig. 7(b) for IF steel. The left figure shows the distribution of the kernel average misorientation (KAM) values of the steel substrates, and the right figure shows the hardness distribution over the corresponding depth. Hardness in the figure 
(a)
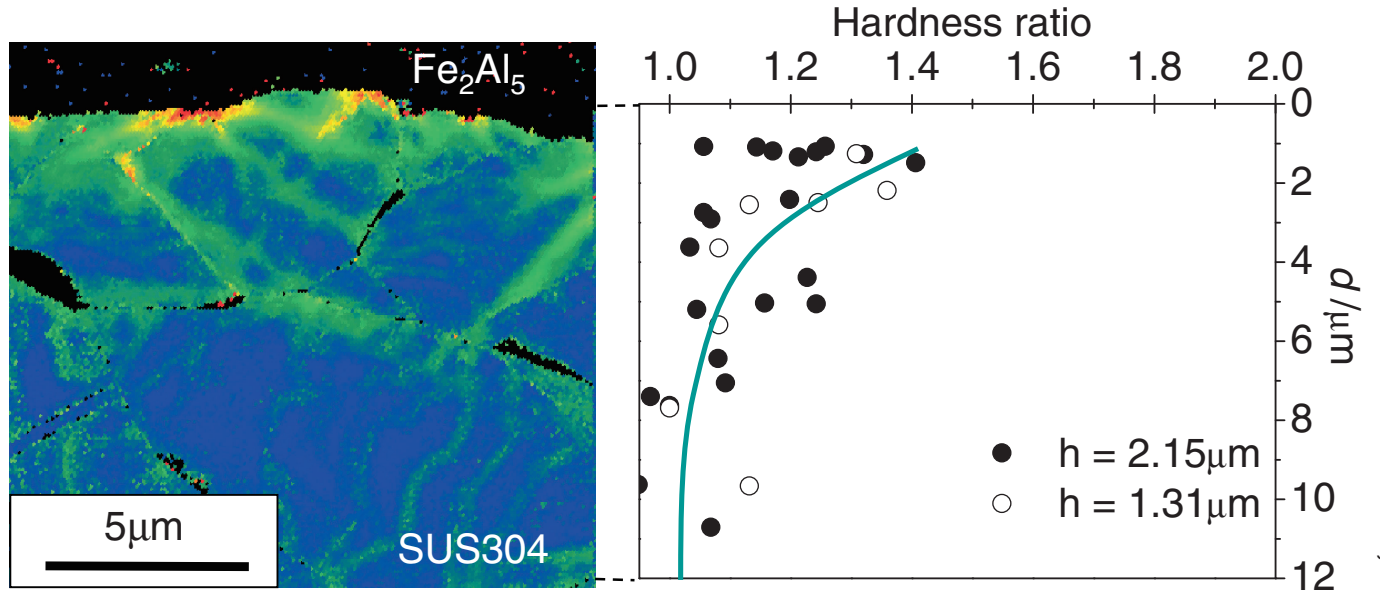

(b)
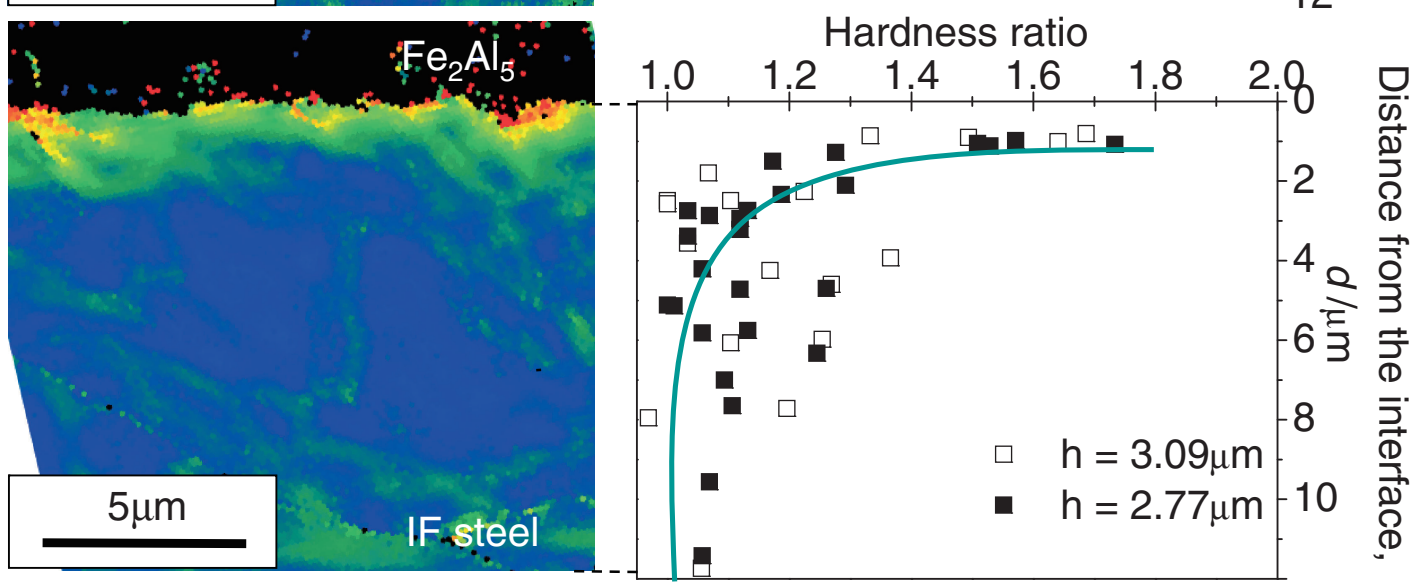

Fig. 7 Distribution of kernel average misorientation and hardness after applying $10 \%$ tensile strain in (a) SUS304 with $2.15 \mu \mathrm{m}$ IMC and (b) IF steel with $3.09 \mu \mathrm{m}$ IMC.

was normalized by the hardness of the base steels distant from the interface. The vertical axis shows the distance of the measurement point from the interface, which corresponds to the left figures. The increase in the KAM values near the interface, as shown in Fig. 7(a), confirms that the steel substrate exhibits a large plastic deformation near the interface where the hardness is correspondingly high. In addition, the results of the hardness test include those measured in the samples with different IMC thicknesses. It is clear that the hardness distribution is almost the same regardless of IMC layer thickness, which supports the result of the numerical analysis by Beuth and Klingbeil. ${ }^{13)} \mathrm{A}$ similar tendency was seen for the IF steel in Fig. 7(b), but compared with the results of for SUS304, hardness rises more steeply in the region closer to the IMC layer. This confirms that the region of plastic deformation is closer to the interface than it is in SUS304 and that IF steel deforms more significantly than SUS304 near the interface.

\subsection{Relationship between IMC thickness and crack interval}

Figure 8 shows plots of the relationship between IMC thickness and crack interval for the samples with tensile strain of $10 \%$. It was confirmed that the crack interval increases with IMC thickness, and even at the same thickness level, there exist several samples whose crack intervals deviate from others, such as those marked with (b) and (c). To investigate the influence of the microstructure, the

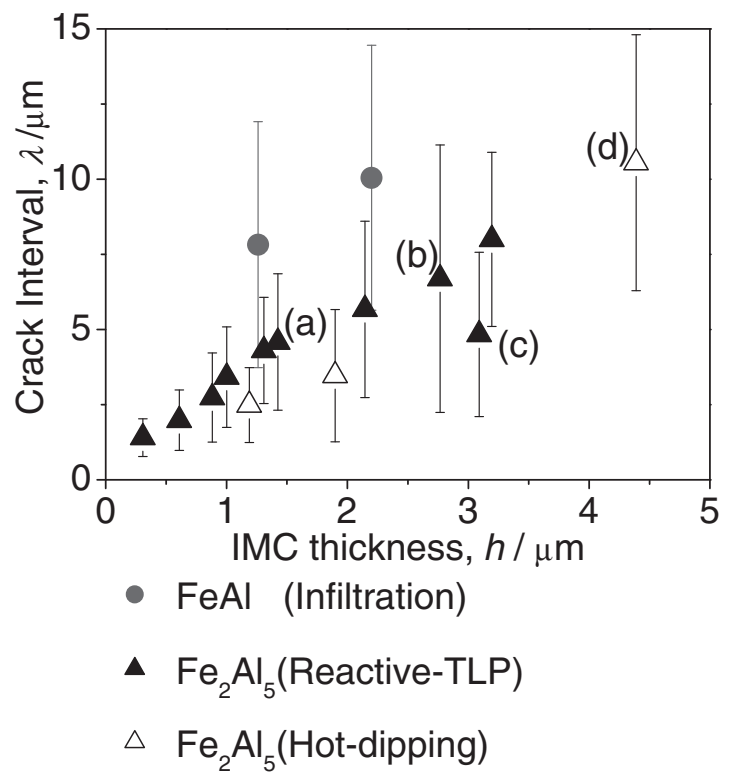

Fig. 8 Relationship between thickness and crack interval of IMC. Microstructure of samples indicated by (a)-(d) are shown in Fig. 9.

microstructure of the IMC was analyzed using EBSD. Figure 9 shows the IQ-map obtained from the samples corresponding to samples (a)-(d) in Fig. 8. It is clear that the microstructure in Fig. 9(c) is different from those of other samples. 


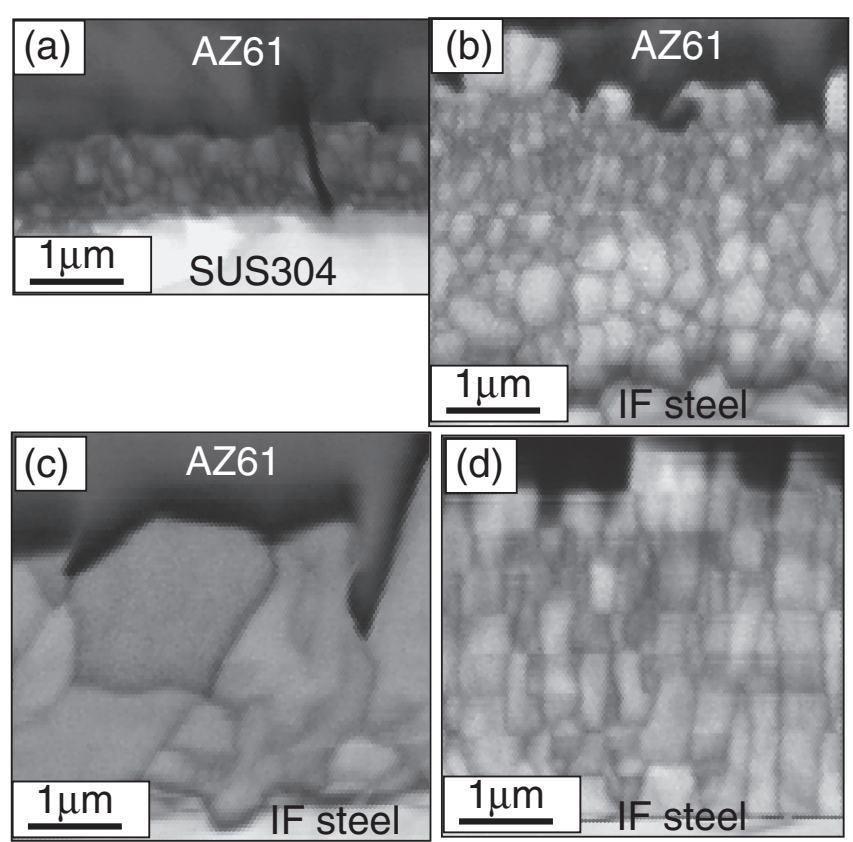

Fig. 9 Microstructures of samples corresponding to those indicated by (a)-(d) in Fig. 8 .
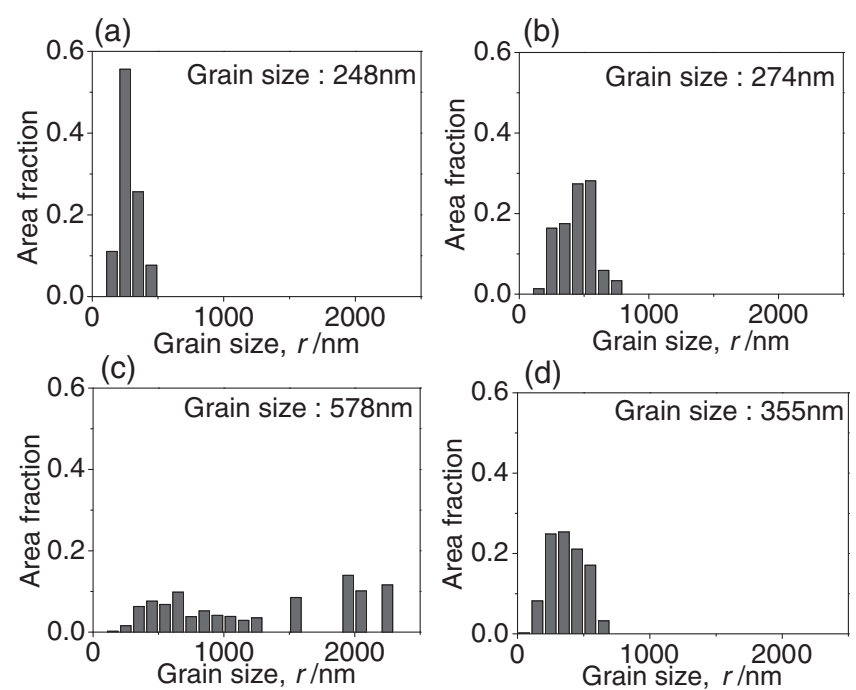

Fig. 10 Grain size distribution of samples corresponding to those indicated by (a)-(d) in Fig. 8.

Figure 10 shows the grain size distribution of the samples shown in Fig. 9. Figures 10(a), 10(b) and 10(d) show similar grain size distributions, where the average grain size is approximately the same. Although the fabrication methods used to produce the samples in Figs. 10(b) and 10(d) were different, the grain size distribution is approximately the same as that shown in Fig. 8. Therefore, we can still regard them as having identical microstructures. On the other hand, in the sample in Fig. 10(c), which contains grains longer than $1 \mu \mathrm{m}$, the average grain size was greater than those in the other types of samples. In the samples composed primarily of $\mathrm{Fe}_{2} \mathrm{Al}_{5}$, we either find $\mathrm{Fe}_{2} \mathrm{Al}_{5}$ with a uniform grain size of $500 \mathrm{~nm}$ or less, as shown in Figs. 10(a), 10(b) and 10(d), or $\mathrm{Fe}_{2} \mathrm{Al}_{5}$ with many coarse grains of sizes greater than $1 \mu \mathrm{m}$, as

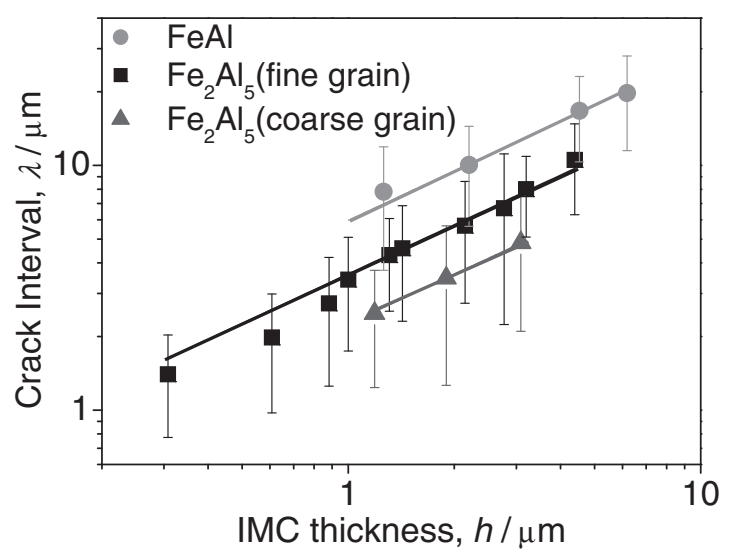

Fig. 11 Relationship between thickness and crack interval for different IMC phases and microstructures.

shown in Fig. 10(c). They are called fine- and coarse-grained $\mathrm{Fe}_{2} \mathrm{Al}_{5}$, respectively, in the following discussion. Figure 11 shows a logarithmic plot of the relationship between the thickness and the crack interval for FeAl and the fine- and coarse-grained $\mathrm{Fe}_{2} \mathrm{Al}_{5}$. Since the crack interval $\lambda_{\mathrm{c}}$ is proportional to the $2 / 3$ power of the IMC layer thickness $h$ according to eq. (4), it is expected that, in the logarithmic representation, the relationship between the thickness and crack interval will be a straight line with a slope of $2 / 3$. In our experiments, it was confirmed that a linear relationship between the thickness and crack interval holds for all microstructures and compositions, with a slope of approximately $2 / 3$.

\subsection{Evaluation of fracture toughness}

Fracture toughness can be evaluated from the intercept of the straight lines in Fig. 11 for each respective microstructure using eq. (4). Young's modulus of $260 \mathrm{GPa}$ for $\mathrm{FeAl}^{14)}$ and of $220 \mathrm{GPa}$ for $\mathrm{Fe}_{2} \mathrm{Al}_{5}{ }^{15}$ ) were used. In addition, the stress estimated from the results of the hardness test was used as the effective yield stress $\sigma_{\text {Yeff }}$ of the substrate. As a result, fracture toughness was estimated to be $1.1 \mathrm{MPa} \cdot \mathrm{m}^{1 / 2}$ for FeAl, $0.51 \mathrm{MPa} \cdot \mathrm{m}^{1 / 2}$ for fine-grained $\mathrm{Fe}_{2} \mathrm{Al}_{5}$ and 0.26 $\mathrm{MPa} \cdot \mathrm{m}^{1 / 2}$ for coarse-grained $\mathrm{Fe}_{2} \mathrm{Al}_{5}$.

Previously reported measurements of bulk materials have revealed that the fracture toughness is $5 \mathrm{MPa} \cdot \mathrm{m}^{1 / 2}{ }^{16}$ ) for $\mathrm{Fe}-$ $\mathrm{Al}(40 \% \mathrm{Al})$ and $\left.0.34 \mathrm{MPa} \cdot \mathrm{m}^{1 / 2} 17\right)$ for $\mathrm{Fe}_{2} \mathrm{Al}_{5}$. It is difficult to directly compare these values, because chemical compositions and microstructures of the IMCs used in the previous measurements differ from those in our study. However, the fracture toughness values obtained are roughly the same as those reported previously, and it can be said that the fracture toughness seems to have a similar dependence on the phase.

\section{Conclusions}

In this study, the fracture toughness of the brittle thin $\mathrm{Fe}-\mathrm{Al}$ IMC layer formed at the interface between dissimilar metals was estimated by a method based on fracture mechanics, considering the plastic deformation of the substrate. The following conclusions were drawn in this study. 
(1) The relationship $\lambda_{\mathrm{c}} \propto h^{2 / 3}$ holds between the thickness $h$ of the brittle thin layer and the crack interval $\lambda_{\mathrm{c}}$, and the fracture toughness was evaluated by measuring $\lambda_{\mathrm{c}}$.

(2) The experimentally obtained fracture toughness values were $1.1 \mathrm{MPa} \cdot \mathrm{m}^{1 / 2}$ for $\mathrm{FeAl}, 0.51 \mathrm{MPa} \cdot \mathrm{m}^{1 / 2}$ for finegrained $\mathrm{Fe}_{2} \mathrm{Al}_{5}$ and $0.26 \mathrm{MPa} \cdot \mathrm{m}^{1 / 2}$ for coarse-grained $\mathrm{Fe}_{2} \mathrm{Al}_{5}$. These results indicate that higher fracture toughness can be obtained by using an iron-rich phase and finer grained microstructures.

\section{REFERENCES}

1) H. Oikawa, T. Saitoh, T. Nagase and T. Kiriyama: Tetsu-to-Hagane 83 (1997) 641-646.

2) S. Mukae, K. Nishio, M. Katoh, T. Inoue and K. Sumitomo: Q. J. JWS 12 (1994) 528-533.

3) T. Araki, M. Koba, S. Nambu, J. Inoue and T. Koseki: Mater. Trans. 52 (2011) 568-571.

4) A. G. Evans and E. A. Charles: J. Am. Ceram. Soc. 59 (1976) 371-372
5) K. I. Schiffmann: Philos. Mag. 91 (2011) 1163-1178.

6) M. S. Hu, M. D. Thouless and A. G. Evans: Acta Metall. 36 (1988) 1301-1307.

7) M. S. Hu and A. G. Evans: Acta Metall. 37 (1989) 917-925.

8) M. D. Thouless, E. Olsson and A. Gupta: Acta Metal. Mater. 40 (1992) 1287-1292.

9) J. S. Wang, Y. Sugimura, A. G. Evans and W. K. Tredway: Thin Solid Films 325 (1998) 163-174.

10) S. Ben Amor, G. Baud, M. Benmalek, H. Dunlop, R. Frier and M. Jacquet: J. Adhesion 65 (1998) 307-329.

11) S. R. Kim and J. A. Nairn: Eng. Fract. Mech. 65 (2000) 573-593.

12) M. D. Thouless: J. Am. Ceram. Soc. 73 (1990) 2144-2146.

13) J. L. Beuth and N. W. Klingbeil: J. Mech. Phys. Solids 44 (1996) 14111428 .

14) M. R. Harmouche and A. Wolfenden: Mater. Sci. Eng. 84 (1986) 35-42.

15) P. Peyre, G. Sierra, F. Deschaux-Beaume, D. Stuart and G. Fras: Mater. Sci. Eng. A 444 (2007) 327-338.

16) M. A. Morris-Muñoz, A. Dodge and D. G. Morris: Nano-Struct. Mater. 11 (1999) 873-885.

17) S. Kobayashi and T. Yakou: Mater. Sci. Eng. A 338 (2002) 44-53. 